\title{
CONSTITUTIVE MODEL OF WATER-SATURATED MARBLE UNDER COUPLING EFFECTS OF UNIAXIAL IMPACT COMPRESSIVE LOADING AND LOW-TEMPERATURE
}

\author{
Junzhe LI, Guang ZHANG, Mingze LIU *, Shaohua HU and Xinlong ZHOU
}

School of Safety Science and Emergency Management, Wuhan University of Technology, Wuhan, Hubei 430071, China

*Corresponding author's e-mail: 1iu107098261@163.com

\begin{tabular}{l} 
ARTICLE INFO \\
\hline Article history: \\
Received 30 November 2019 \\
Accepted 5 February 2020 \\
Available online 5 March 2020 \\
\hline Keywords: \\
Damage constitutive model \\
Impact load \\
Frozen rock \\
Component combination \\
Weibull distribution
\end{tabular}

\begin{abstract}
The study of the mechanical properties of frozen rock is a basic problem that humans have to face in artificial low-temperature rock engineering and cold region rock engineering. There are few literatures on the dynamic constitutive models of frozen rocks under low-temperature gradients at home and abroad. In this paper, the constitutive model of water-saturated marble under the coupling effects of uniaxial impact compressive load and low-temperature is studied by theoretical analysis and experimental verification. Based on the theory of mechanical element combination, a rock constitutive model considering strain rate effect, damage softening effect and low-temperature effect is established, and the model parameters are determined by fitting method. The dynamic stress-strain curve of water-saturated marble at $-30{ }^{\circ} \mathrm{C}$ is predicted. The predicted results are in good agreement with the experimental results and the concordance correlation coefficient is 0.984092 . The relevant results of this paper can provide a theoretical reference for the excavation and protection of rock engineering under negative temperature.
\end{abstract}

\section{INTRODUCTION}

Natural low-temperature rock engineering in cold regions, such as rock slope, roadbed, building foundation and tunnel, while artificial low-temperature rock engineering, such as underground cryogenic storage of liquefied natural gas as well as freezing sinking and driving engineering, are facing with certain excavation or impact protection problems. Scholars have done a lot of research on the mechanical properties of rocks at low-temperature, and have achieved some results. Yamabe et al. (2001) measured the elastic modulus and strength of rock at lowtemperature. Liu et al. (2006) tested water-saturated red sandstone and shale at different low-temperatures, and obtained the results that rock compressive strength, Young's modulus, cohesion and friction angle increase with the decrease of temperature. The uniaxial compression and tensile tests demonstrated by Inada et al. (1984) showed that the tensile strength, compressive strength and elastic modulus of water-saturated rock specimens increase with the decrease of temperature. $\mathrm{Xu}$ et al. (2006) and Yang et al. (2010) carried out the compression test of water-saturated rock at lowtemperature, and obtained the results of the increase of uniaxial compressive strength and elastic modulus of rock from $20^{\circ} \mathrm{C}$ to $-20^{\circ} \mathrm{C}$. The dynamic compressive test of water- saturated sandstone in the range of $-5{ }^{\circ} \mathrm{C}$ to $-30{ }^{\circ} \mathrm{C}$ was carried out, and the result showed that the dynamic compressive strength of frozen rock increased with the decrease of freezing temperature (i.e., low-temperature hardening effect) (Wen et al., 2017). A one-dimensional and three-dimensional constitutive model considering the damage effect of rock under medium strain rate is established by using the combined model method (Li et al., 2006). Zuo et al. (2010) established a dynamic damage model considering plastic deformation based on the mesodamage model. Hamdi et al. (2011) used digital image technology to quantitatively evaluate the damage of rock under impact load, and established the corresponding constitutive model. Cao et al. (2010) established a statistical damage evolution equation reflecting the whole process of rock rupture based on the energy principle of rock material yield or failures. Zhai et al. (2011) established a viscoelastic-plastic dynamic constitutive model considering damage and derived the differential expression of the constitutive equation. Zhu et al. (2013) used a linear viscoelastic model to describe the dynamic constitutive relation of ice under axially graded cyclic dynamic stress load. It found that the dynamic elastic modulus of ice increased with the decrease of temperature; the viscosity coefficient decreased with the decrease of temperature in the range of $0{ }^{\circ} \mathrm{C}-2{ }^{\circ} \mathrm{C}$. Shan et al. (2018) used SHPB device to conduct a uniaxial impact compression test on $-15^{\circ} \mathrm{C}$ water-saturated red sandstone. Based on damage evolution and component model theory, an aging damage model including damage body 
components, clay pots and springs was established to reflect the stress-strain relationship of frozen red sandstone.

In short, the following points can be drawn:

(1) There are many researches on rock constitutive models subjected to freeze-thaw cycles, but less on rock constitutive models under long-term frozen state;

(2) There are many literatures on the static constitutive model of frozen rock at home and abroad, but few on the dynamic constitutive model of frozen rock, especially the open literatures on the dynamic constitutive model of frozen rock under lowtemperature gradients. Therefore, in the engineering practice of excavation and impact protection of frozen rock, only the rock constitutive model under normal temperature can be used, which often fails to achieve good engineering effect

The main part of this text is organized as follows. In section 2, a parallel body composed of Hook spring and Maxwell body is used to simulate the viscoelasticity of rock materials. In section 3 , the strength criterion of Drucker-Prager is used to determine the measured variable $F$ in the Weibull distribution function describing the isotropic damage during loading. The constitutive model is extended from one-dimensional to three-dimensional to adapt to the loading of complex stress-strain states. In sections 4 and 5, the damage evolution law with lowtemperature and constitutive model parameters are determined by theoretical analysis and numerical fitting. In Section 6, the prediction validation and discussions of our established model are performed. The relevant results can provide a theoretical reference for the excavation and impact protection of low-temperature rock engineering.

\section{DERIVATION OF THE CONSTITUTIVE MODEL IN THE UNDAMAGED STATE}

Under the uniaxial impact compressive load, the component combination model shown in Figure 1 is used to describe the mechanical behavior of the rock in the undamaged state. The model is a parallel system consisting of a Hooke spring and a Maxwell body. The Maxwell body is the system consisting of a Hooke spring $E_{1}$ and a Newtonian pot $\eta$ in series. The stress and strain on the model are denoted by $\sigma$ and $\varepsilon$, that on the Hooke spring are denoted by $\sigma_{1}$ and $\varepsilon_{1}$ and that on the Maxwell body are denoted by $\sigma_{2}$ and $\varepsilon_{2}$ respectively.

The stress-strain relationship of Hooke spring $E_{0}$ is shown in Eq. (1):

$\sigma_{1}=E_{0} \varepsilon_{1}$

The stress-strain relationship of Maxwell body is shown in Eq. (2):

$\frac{\dot{\sigma}_{2}}{E_{1}}+\frac{\sigma_{2}}{\eta}=\dot{\varepsilon}_{2}$

Where, the point is the first-order derivative of time.

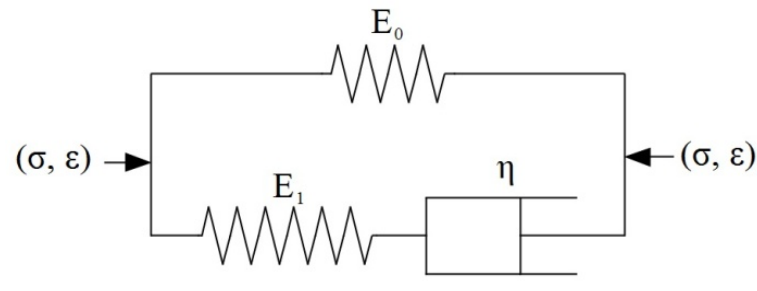

Fig.1 Constitutive model of rock in undamaged state.

The relationship between the stress, strain and strain rate on the parallel system is given by Eq. (3):

$\sigma=\sigma_{1}+\sigma_{2}$

$\varepsilon=\varepsilon_{1}=\varepsilon_{2}$

$\dot{\varepsilon}=\dot{\varepsilon}_{1}=\dot{\varepsilon}_{2}$

According to Eq. (3c), if the constant strain rate load is applied to the parallel system, then $\varepsilon_{2}=\dot{\varepsilon}_{2} t$ remains precisely. Eq. (4) can be obtained by performing the Laplace transformation on both sides of Eq. (2):

$\frac{s L\left(\sigma_{2}\right)}{E_{1}}+\frac{L\left(\sigma_{2}\right)}{\eta}=\frac{\dot{\varepsilon}_{2}}{s}$

Where, $s$ is $1 / \int_{0}^{+\infty} e^{-s t} d t . L\left(\sigma_{1}\right)$ and $L\left(\sigma_{2}\right)$ are the results of the Laplace transformation of $\sigma_{1}$ and $\sigma_{2}$ respectively.

Eq. (4) is further transformed into Eq. (5):

$L\left(\sigma_{2}\right)=E_{1} \dot{\varepsilon}_{2} \varphi \frac{\varphi^{-1}}{s\left(s+\varphi^{-1}\right)}$

where, $\varphi$ is $\eta / E_{1}$.

The inverse Laplace transform is performed on left and right sides of Eq. (5). By substituting into the initial condition $\sigma_{2}(t=0)=0$, the result of inverse Laplace transform can be obtained:

$\sigma_{2}=E_{1} \dot{\varepsilon}_{2} \varphi\left(1-\exp \left(-\frac{t}{\varphi}\right)\right)$

By substituting $\varepsilon_{2}=\dot{\varepsilon}_{2} t$ into Eq. (6), Eq. (7) can be obtained:

$\sigma_{2}=E_{1} \dot{\varepsilon}_{2} \varphi\left(1-\exp \left(-\frac{\varepsilon_{2}}{\dot{\varepsilon}_{2} \varphi}\right)\right)$

By substituting Eqs. (1), (7), (3b) and (3c) into Eq. (3a), Eq. (8) can be obtained:

$\sigma=E_{0} \varepsilon+E_{1} \dot{\varepsilon} \varphi\left(1-\exp \left(-\frac{\varepsilon}{\dot{\varepsilon} \varphi}\right)\right)$

Using $\sigma=E_{s} \varepsilon$ to replace Eq. (8), Eq. (9) can be obtained: 


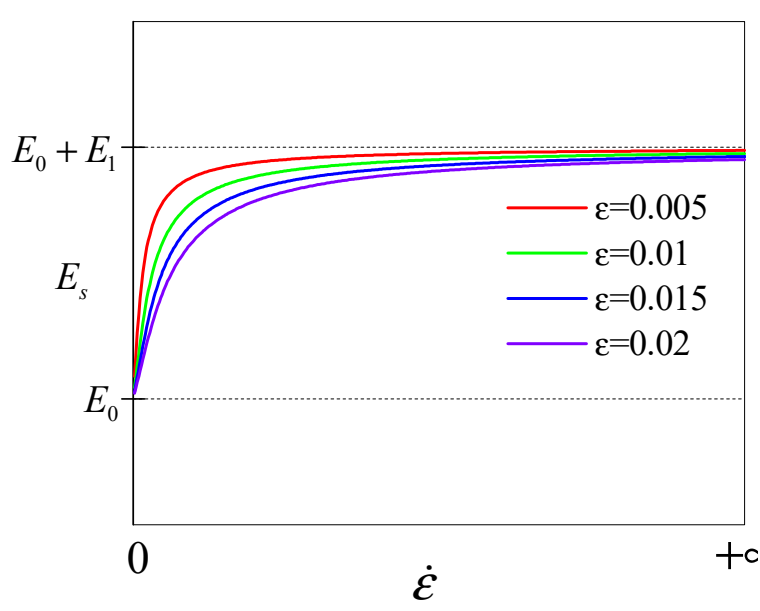

Fig. $2 E_{s}(\dot{\varepsilon})$ curve at different strain locations.

$$
E_{s}=E_{0}+\frac{E_{1} \varphi \dot{\varepsilon}}{\varepsilon}\left(1-\exp \left(-\frac{\varepsilon}{\dot{\varepsilon} \varphi}\right)\right)
$$

where, $E_{s}$ is the secant modulus of elasticity.

It should be noted that for a reasonable viscoelastic model reflecting the initial deformation of geotechnical materials under load, the following two conditions should be met at least (Zheng et al., 1997): (i) the instantaneous strain would occur (i.e., the elastic modulus is not infinite) under high-rate load, and (ii) there is still a certain size of elastic modulus (i.e., the elastic modulus is not zero) under quasielastic load. By calculating the limit of Eq. (9), $\lim _{\dot{\varepsilon} \rightarrow+\infty} E_{s}=E_{0}+E_{1} \neq \infty$ and $\lim _{\dot{\varepsilon} \rightarrow 0} E_{s}=E_{0} \neq 0$ can be obtained, which represent that the model shown in Figure 1 satisfies conditions (1) and (2). It can also be judged by the relationship between $E_{s}$ and $\dot{\varepsilon}$ as shown in Figure 2. In a word, the component combination model shown in Figure 1 is suitable for describing the mechanical behavior of the rock in the undamaged state. The model parameter $E_{0}$ represents the static elastic modulus of the rock material, and the model parameter $E_{1}$ represents the increment of the elastic modulus of the rock material relative to the static elastic modulus under dynamic loading.

\section{STATISTICAL DAMAGE CONSTITUTIVE MODEL AND PARAMETER ANALYSIS}

According to the strain equivalence hypothesis (Lemaitre, 1985), the constitutive relation of damaged rocks can be expressed as Eq. (11):

$$
\sigma=(1-D) \sigma^{*}
$$

Where, $\sigma^{*}$ is the effective stress. $\sigma$ and $D$ are the nominal stress and the damage variable respectively. The key to establish a constitutive relation of rock is to determine the damage variable.

There are a large number of microscopic defects inside the rock. If the rock is regarded as a combination of mesoscopic elements, each element has different strength due to different defects. If it is assumed that the strength of the elements obeys the Weibull distribution law, and the damage variable is defined as the ratio of the number of failed elements to the total number of elements, the following equation (Wang et al., 2007) can be derived:

$D=1-\exp \left(-\left(\frac{F}{F_{0}}\right)^{m}\right)$

where, $F$ is the measure of the strength or stress (or strain) level of the mesoscopic element. $F_{0}$ and $m$ are the Weibull parameters reflecting the distribution characteristics of the strength of mesoscopic element respectively.

Eq. (11) is the damage evolution equation in the statistical constitutive model of the rock. Next, the influence of parameters in the damage evolution equation is analyzed. Figure 3(a) shows the variations of damage variable $D$ with $F$ for the same $m$ and different $F_{0}$. The damage variable $D$ increases with the increase of $F$. At the same $F$, larger $F_{0}$ implies smaller damage, which means that the fully damaged state can be achieved more easily. $F_{0}$ reflects the strength level of mesoscopic elements in the rock and the macro strength of the rock. Figure 3(b) shows the variations of damage variable $D$ with $F$ for same $F_{0}$ and different $m$. The slope of the non-horizontal section of the $D-F$ curve reflects the uniformity of the strength mesoscopic element in the rock. A larger slope indicates a greater difference in strength between the mesoscopic elements, which means that the brittleness of rock is more obvious (Zhou et al., 2017).

Eq. (12) can be derived by substituting Eq. (8) into Eq. (10):

$$
\sigma=(1-D)\left(E_{0} \varepsilon+E_{1} \varphi \dot{\varepsilon}\left(1-\exp \left(-\frac{\varepsilon}{\dot{\varepsilon} \varphi}\right)\right)\right)
$$

It should be noted that Eq. (12) is only applicable in the case that no initial stress and uniaxial impact load. The following shows the case without initial stress and simultaneous triaxial impact load. The damage is assumed to be isotropic. Based on the idea that the constitutive relation of Hooke spring is extended from one dimension to three dimensions, the three-dimensional constitutive relation of the model with damage can be expressed as follows:

$$
\begin{aligned}
& \sigma_{i}=(1-D) \frac{1}{1+v}\left(E_{0} \varepsilon_{i}+\eta \dot{\varepsilon}_{i}\left(1-\exp \left(-\frac{\varepsilon_{i}}{\dot{\varepsilon}_{i} \varphi}\right)\right)\right) \\
& +(1-D) \frac{v}{(1-2 v)(1+v)}\left(E_{0} \varepsilon_{V}+\eta \dot{\varepsilon}_{V}\left(1-\exp \left(-\frac{\varepsilon_{V}}{\dot{\varepsilon}_{V} \varphi}\right)\right)\right)
\end{aligned}
$$

where, $\sigma_{i}$ represents the principal stress; $i=1,2,3, i$ is the three principal directions; $\varepsilon_{i}$ is the strain in the principal direction; $\varepsilon_{V}=\varepsilon_{1}+\varepsilon_{2}+\varepsilon_{3}, \quad \varepsilon_{V}$ is the 


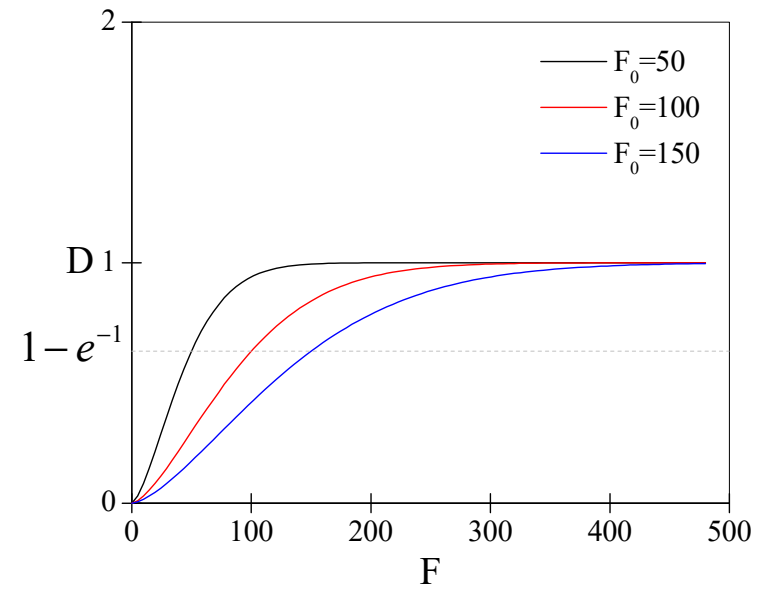

(a) Effects of $F_{0}$ on $F$-D curves

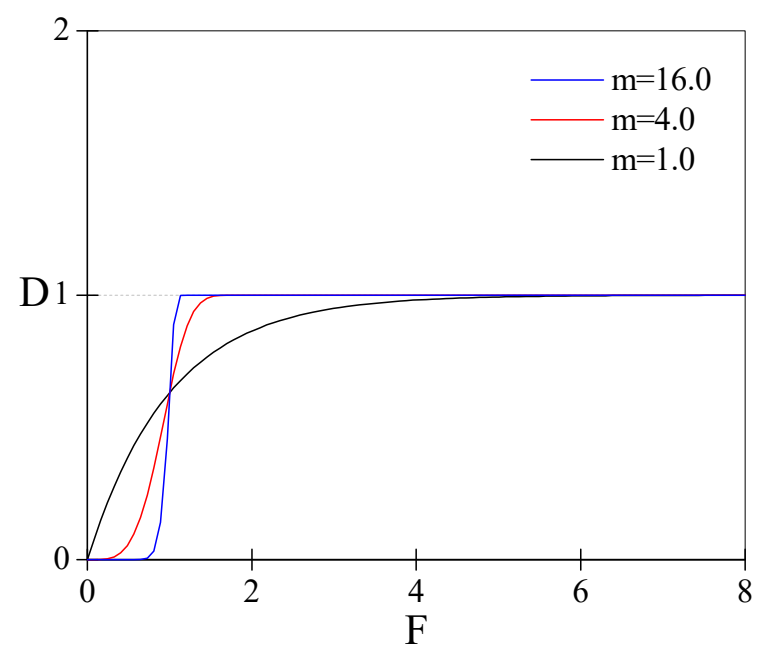

(b) Effects of $m$ on $F-D$ curves

Fig. 3 Effects of model parameters on $F-D$ curves.

volumetric strain and $v$ is the Poisson ratio of the rock.

In practice, the strain (or stress) state of the rock is very complex, and a constitutive model that reflects the complicated strain state is needed. The strain state of rock before loading $\left(\varepsilon_{1}^{0}, \varepsilon_{2}^{0}, \varepsilon_{3}^{0}\right)$ can be calculated from the initial stress state. The strain is additive. Thus, Eq. (13) can be further transformed into:

$$
\begin{aligned}
& \sigma_{i}=(1-D) \frac{1}{1+v}\left(E_{0}\left(\varepsilon_{i}+\varepsilon_{1}^{0}\right)+\eta \dot{\varepsilon}_{i}\left(1-\exp \left(-\frac{\varepsilon_{i}}{\dot{\varepsilon}_{i} \varphi}\right)\right)\right) \\
& +(1-D) \frac{v}{(1-2 v)(1+v)}\left(E_{0}\left(\varepsilon_{V}+\varepsilon_{V}^{0}\right)+\eta \dot{\varepsilon}_{V}\left(1-\exp \left(-\frac{\varepsilon_{V}}{\dot{\varepsilon}_{V} \varphi}\right)\right)\right)
\end{aligned}
$$

where, $\varepsilon_{1}^{0}$ and $\varepsilon_{V}^{0}$ represent the principal strain and volumetric strain before loading respectively. $\varepsilon_{i}$ and $\varepsilon_{V}$ represent the principal strain and volumetric strain during loading respectively.

Similar to the elastic theory, the above equation can be written as:

$$
\sigma_{i}=(1-D)\left(E_{0}\left(\varepsilon_{i}+\varepsilon_{1}^{0}\right)+\eta \dot{\varepsilon}_{i}\left(1-\exp \left(-\frac{\varepsilon_{i}}{\dot{\varepsilon}_{i} \varphi}\right)\right)\right)+v\left(\sigma_{j}+\sigma_{k}\right.
$$

In general, the variable $F$ for damage measure is directly regarded as the strain (Wang et al., 2018). However, the distribution of the failed mesoscopic elements cannot be precisely represented only by the uniaxial stress or strain (Liu et al., 2018). In this paper, the Drucker-Prager strength criterion is adopted to determine variable $F$. In order to make it suitable for uniaxial and triaxial stress states, the corresponding improvements have been made. The results show the sign rules adopted in geomechanics, i.e., compressive stress and strain are assigned as positive signs. $F$ is given as Eq. (16):

$$
F=\left(\frac{3-\sin \varphi}{3-3 \sin \varphi}\right)\left(\sqrt{3 J_{2}\left(\sigma^{*}\right)}-\frac{2 \sin \varphi}{3-\sin \varphi} I_{1}\left(\sigma^{*}\right)\right)
$$

Where, $I_{1}\left(\sigma^{*}\right)$ is the first invariant of the effective stress tensor $\sigma^{*} ; J_{2}\left(\sigma^{*}\right)$ is the second invariant of the effective stress deviator $s\left(\sigma^{*}\right)$, and $\phi$ is the internal friction angle. The effective stress tensor $\sigma^{*}$ can be obtained by the following equation:

$$
\begin{aligned}
& \sigma_{i}=\frac{1}{1+v}\left(E_{0}\left(\varepsilon_{i}+\varepsilon_{1}^{0}\right)+\eta \dot{\varepsilon}_{i}\left(1-\exp \left(-\frac{\varepsilon_{i}}{\dot{\varepsilon}_{i} \varphi}\right)\right)\right) \\
& +\frac{v}{(1-2 v)(1+v)}\left(E_{0}\left(\varepsilon_{V}+\varepsilon_{V}^{0}\right)+\eta \dot{\varepsilon}_{V}\left(1-\exp \left(-\frac{\varepsilon_{V}}{\dot{\varepsilon}_{V} \varphi}\right)\right)\right)
\end{aligned}
$$

Obviously, the constitutive relation under the initial stress state with zero value and uniaxial impact load is as follows:

$\sigma=\exp \left(-\left(\frac{\sigma^{*}}{F_{0}}\right)^{m}\right) \sigma^{*}$

Where, $\sigma^{*}=E_{s} \varepsilon=\left(E_{0} \varepsilon+E_{1} \varphi \dot{\varepsilon}(1-\exp (-\varepsilon / \dot{\varepsilon} \varphi))\right)$ is the effective stress.

The parameters $E_{0}, E_{1}$ and $\varphi$ can be determined by fitting the undamaged section of the stress-strain test curve, and the analytical solutions of $m$ and $F_{0}$ can be obtained by Eqs. (19)-(22). Otherwise, the exact values of all model parameters can only be obtained by fitting the full stress-strain test curve. The latter is used in this paper.

Further deformation of Eq. (18) is available:

$$
\frac{d \sigma}{d \varepsilon}=\frac{d\left(E_{s} \varepsilon\right)}{d \varepsilon} \exp \left(-\left(\frac{E_{s} \varepsilon}{F_{0}}\right)^{m}\right)\left(1-m\left(\frac{E_{s} \varepsilon}{F_{0}}\right)^{m}\right)
$$


At the peak of the constitutive curve, $\varepsilon=\varepsilon_{c}$ and $d \sigma_{1} / d \varepsilon_{1}=0$ are true. Substituting this condition into Eq. (19), Eq. (20) can be derived:

$F_{0}=m^{\frac{1}{m}}\left(E_{0} \varepsilon_{c}+E_{1} \dot{\varepsilon} \varphi\left(1-\exp \left(-\varepsilon_{c} / \dot{\varepsilon} \varphi\right)\right)\right)$

The stress-strain relation at the peak point is $\sigma_{c}=\exp \left(-\left(E_{s} \varepsilon_{c} / F_{0}\right)^{m}\right) E_{s} \varepsilon_{c}$. By combining the equation with Eq. (20), the Weibull parameter $m$ can be determined as follows:

$$
m=\frac{1}{\ln \left(E_{s} \varepsilon_{c} / \sigma_{c}\right)}
$$

Substituting Eq. (21) into Eq. (19), the Weibull parameter $F_{0}$ can be known as follows:

$$
F_{0}=\frac{E_{0} \varepsilon_{c}+E_{1} \dot{\varepsilon} \varphi\left(1-\exp \left(-\varepsilon_{c} / \dot{\varepsilon} \varphi\right)\right)}{\ln \left(E_{s} \varepsilon_{c} / \sigma_{c}\right)^{\ln \left(E_{s} \varepsilon_{c} / \sigma_{c}\right)}}
$$

\section{VERIFICATION OF STATISTICAL DAMAGE CONSTITUTIVE MODEL}

The predicted application of the proposed model in $3 \mathrm{D}$ condition is not presented in this work. The next section is a preliminary study on the model. The main purpose is to verify the results. More data about the proposed prediction model will be collected and studied in the future work.

In the classical definition of damage (Liu et al., 2014), damage represents the change rate of elastic modulus. Therefore, only the elastic modulus is damaged during loading (i.e., the damage only appears on the parameter with dimension $\mathrm{Pa}$ ). As shown in Table 1, among the three parameters of Eq. (8), only the dimension of $E_{0}$ and $E_{1}$ is $G P a$, and the dimension of $\varphi$ is $\mu s$. If the damage effect is considered, the model shown in Figure 1 can be expressed by Eq. (23):

$$
\sigma=\left((1-D) E_{0} \varepsilon+(1-D) E_{1} \varphi \dot{\varepsilon}\left(1-\exp \left(-\frac{\varepsilon}{\varphi \dot{\varepsilon}}\right)\right)\right)
$$

The results show that Eq. (23) and Eq. (12) (based on the Lemaitre equivalent strain hypothesis) are identical in form, which proofs that the Lemaitre equivalent strain hypothesis is reasonable.

The parameter estimation algorithm, including the Levenberg-Marquarat algorithm (LM) and the Universal Global Optimization (UGO) (Lan et al., 2009) has strong searching ability and robustness, is a powerful tool for processing curve fitting, which is hereinafter referred to as LM-UGO. The validity of the model can be proved by comparing the test curve with the fitted curve and evaluating the consistency correlation coefficient of the fitting effect. $E_{0}$ represents the static modulus of elasticity of the rock
Table 1 Dimension of model parameters in Eq. (8).

\begin{tabular}{cccc}
\hline Symbol & $E_{0}$ & $E_{1}$ & $\varphi$ \\
\hline Unit & $G P a$ & $G P a$ & $\mu s$ \\
\hline
\end{tabular}

material, and $E_{0}$ is a constant that does not change with the strain rate. $\varphi$ is related to the viscosity of the material. Let $\varphi$ be a constant that does not varies with strain rate. $E_{0}$ and $\varphi$ are the same in the stress-strain relation models at different strain rates, thus the method of sharing parameters can be used to estimate the model parameters during the execution of the LMUGO algorithm. Eq. (18) is suitable for fitting the stress-strain data of water-saturated marble with strain rates $92 s^{-1}, 101 s^{-1}$ and $112 s^{-1}$ (Yang, 2016) respectively. The fitting effect is shown in Figure 4.

By comparing the experimental curve with the theoretical curve and evaluating the concordance correlation coefficients in Figure 4, it can be concluded that Eq. (18) is a good approximation equation. The phenomena shown in Figure 4 demonstrate that the model represented by Eq. (18) is reasonable and applicable to simulate the mechanical behavior of water-saturated marble under uniaxial impact compressive load and assume that $\varphi$ is independent of strain rate. The estimation results of the constitutive model parameters at $-15^{\circ} \mathrm{C}$ and different strain rates are shown in Table 2 . The variation trend of model parameters $E_{1}$ and $D(F)$ with strain rate is shown in Figure 5.

Figure 5(a) shows that the estimated dynamic elastic modulus increases with the increase of strain rate, which is consistent with the general rule obtained by Zhou et al. (2014). As shown in Figure 5(b), the value of $F$ at the beginning of the damage (damage threshold) increases with the increase of strain rate, which indicates that the propagation of micro-cracks in the rock under high-rate load has hysteresis compared with low-rate load. However, the ratio of $F$ at the beginning of the damage to $F$ at the end of the damage is not greatly affected by strain rate. The above results are similar to Xiao et al. (2010) through the compression test of concrete at different strain rates. The phenomena shown in Figures 5(a) and 5(b) also demonstrate that the model represented by Eq. (18) is reasonable and applicable to simulate the mechanical behavior of water-saturated marble under uniaxial impact compressive loading, and assuming that $\varphi$ is independent of the strain rate. With the occurrence of rock material damage, the increase of effective stress value is due to the influence of strain rate on the dynamic characteristics of rock material, which is mainly reflected in the fact that the viscosity of rock material hinders the generation and propagation of microcracks under high strain rate. However, this obstruction also leads to an increase in the effective stress value required for complete 


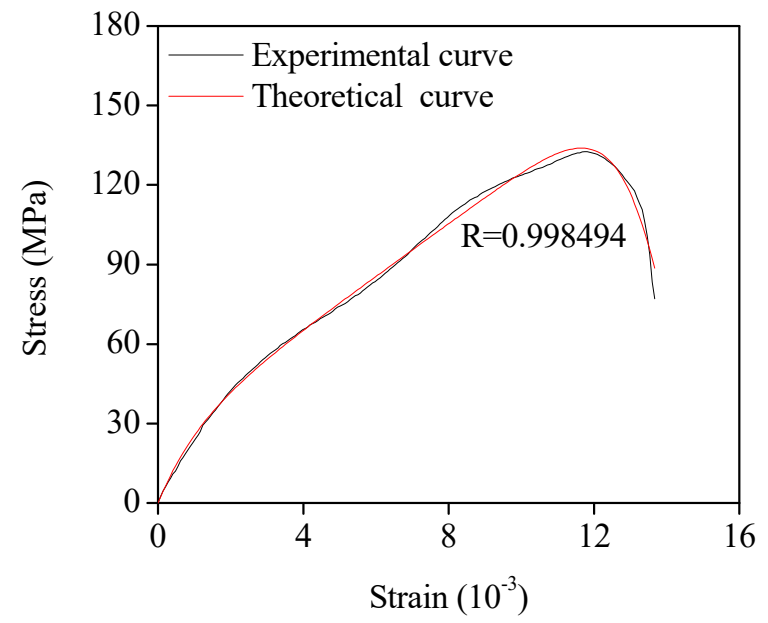

(a) $\dot{\varepsilon}=92 s^{-1}$

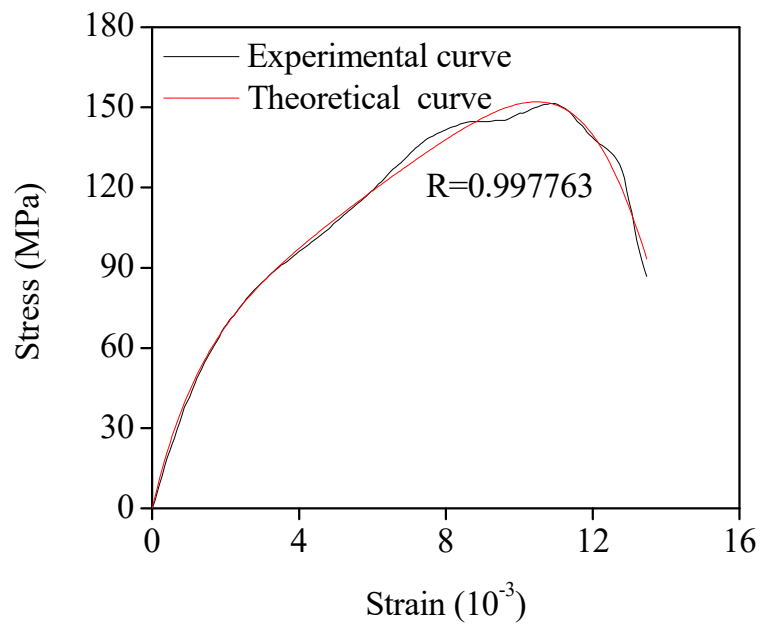

(b) $\dot{\varepsilon}=101 \mathrm{~s}^{-1}$

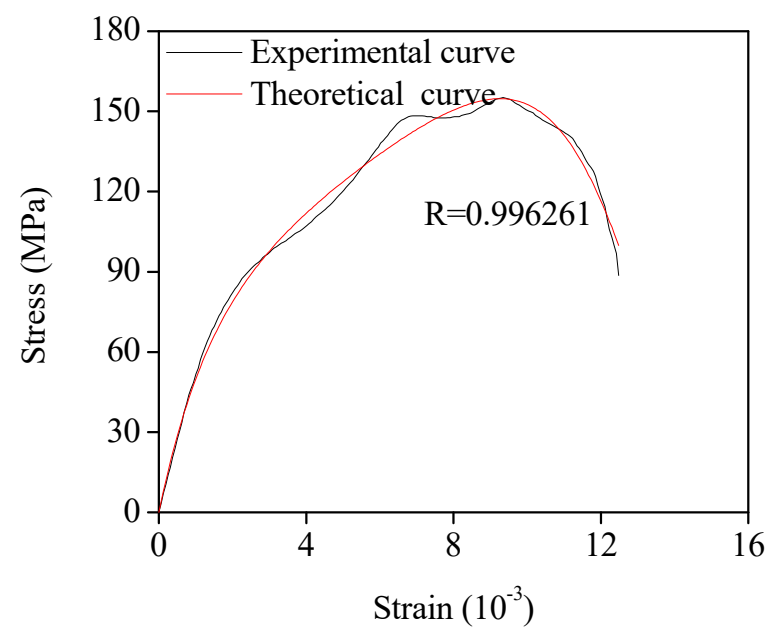

(c) $\dot{\varepsilon}=112 s^{-1}$

Fig. 4 The corresponding theoretical stress-strain curves and experimental results at $-15{ }^{\circ} \mathrm{C}$ and different strain rates.

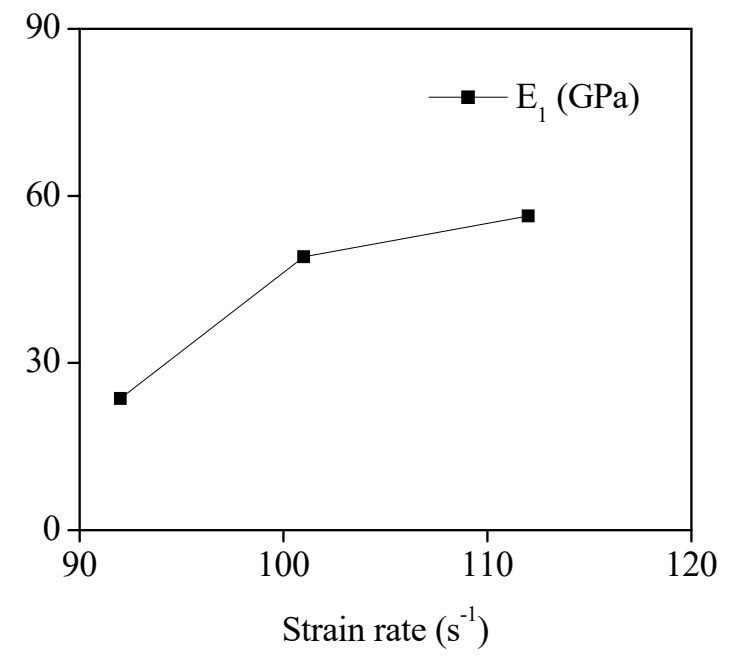

(a) Variation of $E_{1}$ with strain rate

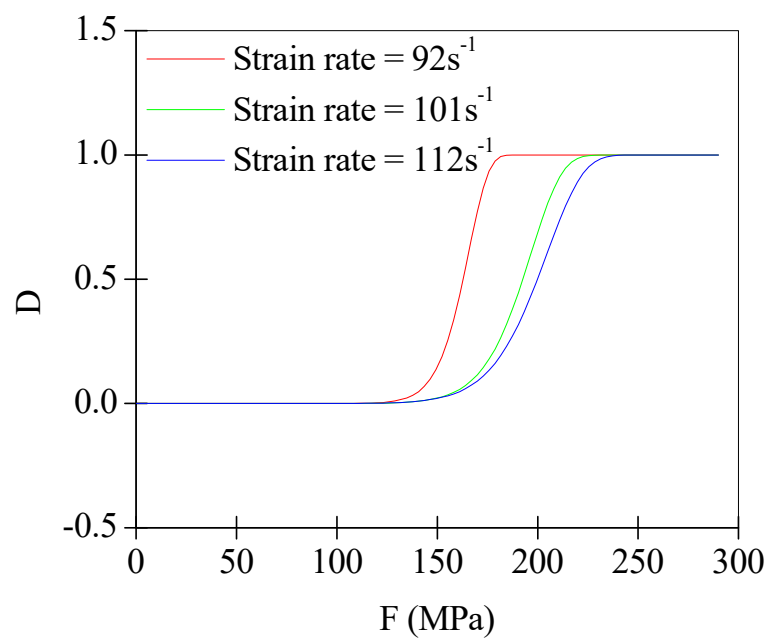

(b) Variation of $D(F)$ with strain rate

Fig. 5 Variation of model parameter with strain rate at $-15{ }^{\circ} \mathrm{C}$. 
Table 2 Fitting results of constitutive model parameters at $-15^{\circ} \mathrm{C}$ and different strain rates.

\begin{tabular}{cccccc}
\hline \multirow{2}{*}{$\dot{\varepsilon} / s^{-1}$} & \multicolumn{5}{c}{ Model parameters } \\
\cline { 2 - 6 } & $E_{0} / G P a$ & $E_{1} / G P a$ & $\varphi / \mu s$ & $F_{0} / M P a$ & $m$ \\
\hline 92 & 9.90208 & 23.611980 & 12.073578 & 166.218964 & 18.000387 \\
101 & 9.90208 & 49.084334 & 12.073578 & 197.800265 & 13.790216 \\
112 & 9.90208 & 56.412452 & 12.073578 & 205.928989 & 12.258390 \\
\hline
\end{tabular}

damage of the rock material. Therefore, the ratio of $F$ at the beginning of the rock material damage to $F$ at the time of complete damage is not greatly affected by the strain rate.

\section{CONSTITUTIVE MODEL AND PARAMETER ANALYSIS OF LOW-TEMPERATURE DAMAGE}

\subsection{CONSTITUTIVE MODEL OF LOW- TEMPERATURE DAMAGE}

Compared with the normal temperature environment, the mechanical properties of water saturated rocks exposed to low-temperature environment are different. The change of elastic modulus is measured by damage. The damage of water-saturated rock caused by low-temperature in this paper is represented by $D_{0}$. According to the definition of damage, if the elastic modulus before the damage is $E_{0}$ and $E_{1}$, the elastic modulus after the damage is $\left(1-D_{0}\right) E_{0}$ and $\left(1-D_{0}\right) E_{1}$. By substituting $\left(1-D_{0}\right) E_{0}$ and $\left(1-D_{0}\right) E_{1}$ for $E_{0}$ and $E_{1}$ in Eq. (18), Eq. (24) can be obtained:

$$
\sigma=\exp \left(-\left(\frac{\left(1-D_{0}\right) E_{s} \varepsilon}{F_{0}}\right)^{m}\right)\left(1-D_{0}\right) E_{s} \varepsilon
$$

Where, $E_{s}$ is the same as in Eq. (8). Eq. (24) is the statistical damage constitutive model of watersaturated rock under the coupling effects of uniaxial impact compressive load and low-temperature.

$D_{0}$ is the function of $T$. The variation law of the elastic modulus with temperature is represented by $D_{0}(T) . E_{0}$ and $E_{1}$ are constants that do not change with temperature. It is assumed that the strength of all mesoscopic elements in rock changes at the same rate with the change of temperature. $m$ is the parameter reflecting the uniformity of the strength of mesoscopic elements. Therefore, the strength of mesoscopic elements in rock changes at the same ratio means that $m$ is a constant that does not change with temperature.

The strength of each mesoscopic element in rock changes with temperature. $F_{0}$ is the parameter reflecting the level of the strength of mesoscopic elements. The inevitable change of mesoscopic element strength in rock means that $F_{0}(T)$ is a function of $T . \varphi$ is a mechanical parameter reflecting the viscosity of rock. $\varphi$ changes with temperature
(Deng et al., 2004), i. e., $\varphi(T)$ is a function of $T$. Based on the analysis, Eq. (24) can be further transformed into Eq. (25):

$$
\sigma=\exp \left(-\left(\frac{\left(1-D_{0}(T)\right) E_{s} \varepsilon}{F_{0}(T)}\right)^{m}\right)\left(1-D_{0}(T)\right) E_{s} \varepsilon
$$

\subsection{DETERMINATION OF MODEL PARAMETERS}

In Section 4, the constitutive model parameters $E_{0}, E_{1}$ and $m$ of water-saturated marble under the conditions of $112 \mathrm{~s}^{-1}$ and $-15{ }^{\circ} \mathrm{C}$ are determined. The model parameters $D_{0}, \varphi$ and $F_{0}$ under different temperatures are estimated by applying the LM-UGO algorithm to fit the stress-strain data obtained from the test.

The model shown in Eq. (24) is applied to the fitting of the stress-strain data of water-saturated marble at strain rate $112 \mathrm{~s}^{-1}$ and different temperatures $\left(+25{ }^{\circ} \mathrm{C},-5{ }^{\circ} \mathrm{C},-10{ }^{\circ} \mathrm{C},-20{ }^{\circ} \mathrm{C}\right.$ and $\left.-40{ }^{\circ} \mathrm{C}\right)$ respectively. The estimated values of the parameters are given in Table 3. The estimated effect is illustrated in Figure 6.

By comparing the test curve with the fitted curve and evaluating the consistency correlation coefficient in Figure 6, it can be seen that the fitting results is consistent with the experimental results, and the model represented by Eq. (24) is reasonable and applicable.

\subsection{MODEL PARAMETER ANALYSIS}

The value of $D_{0}$ at $T=-15^{\circ} \mathrm{C}$ is defined as 0 . The damage of the elastic modulus at different temperatures is shown in Table 3 . In order to distinguish easily, according to the definition of $D_{0}$ as 0 at $T=+25^{\circ} \mathrm{C}, D_{0}^{*}$ is used to represent the damage of elastic modulus at different temperatures $D_{0}^{*}$ can be calculated by Eq. (26):

$$
\left\{\begin{array}{l}
D_{0}^{*}(T)=1-\frac{E_{0}(T)}{E_{0}\left(T=25^{\circ} \mathrm{C}\right)} \\
\text { or } D_{0}^{*}(T)=1-\frac{E_{1}(T)}{E_{1}\left(T=25^{\circ} \mathrm{C}\right)}
\end{array}\right.
$$

Where, $E_{0}(T)$ is $\left(1-D_{0}(T)\right) E_{0}\left(T=-15^{\circ} \mathrm{C}\right)$ and $E_{1}(T)$ is $\left(1-D_{0}(T)\right) E_{1}\left(T=-15^{\circ} \mathrm{C}\right)$. 


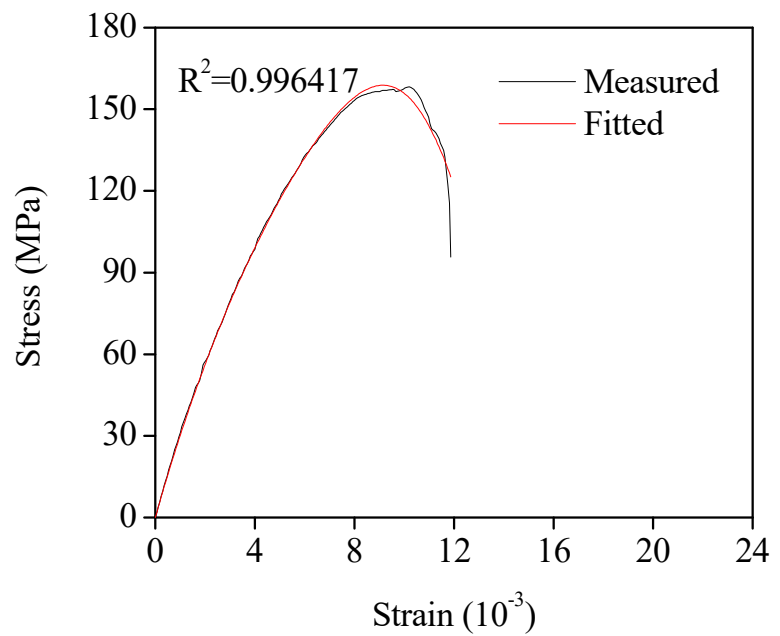

(a) $\mathrm{T}=+25^{\circ} \mathrm{C}$

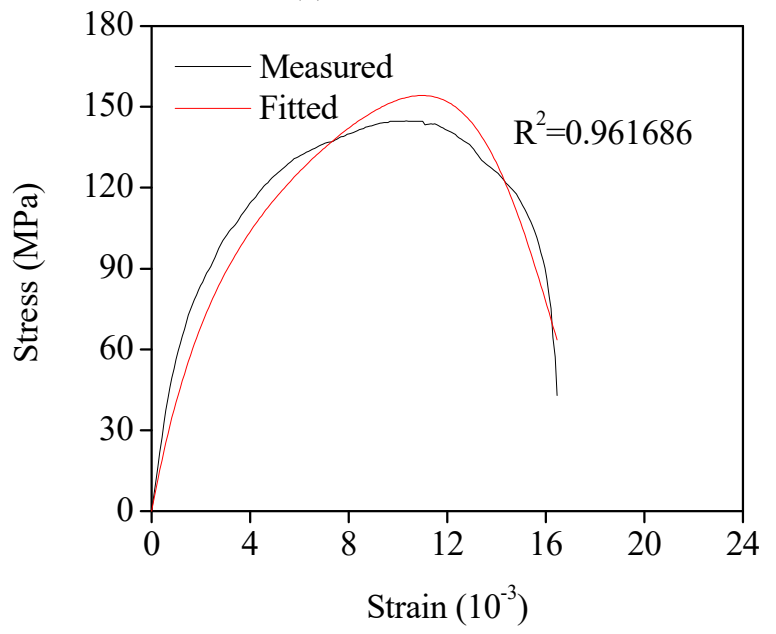

(c) $\mathrm{T}=-10^{\circ} \mathrm{C}$

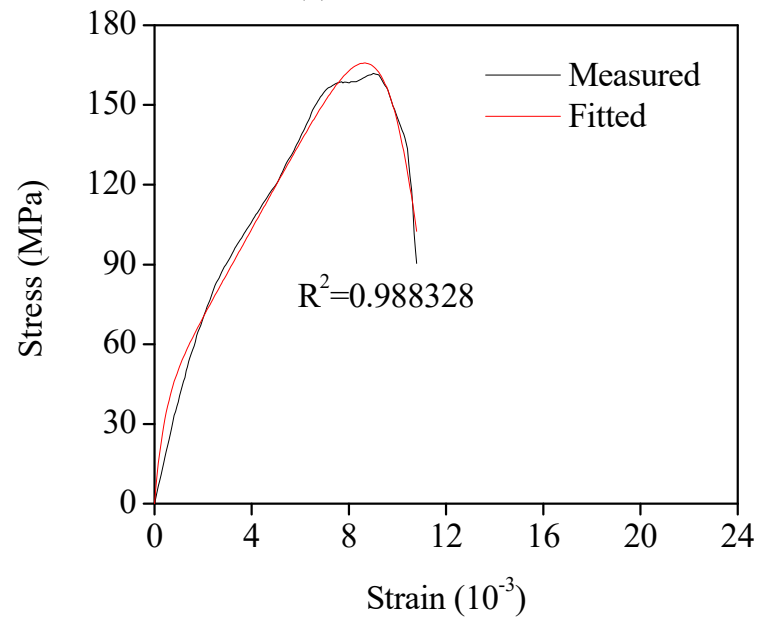

(e) $\mathrm{T}=-20^{\circ} \mathrm{C}$

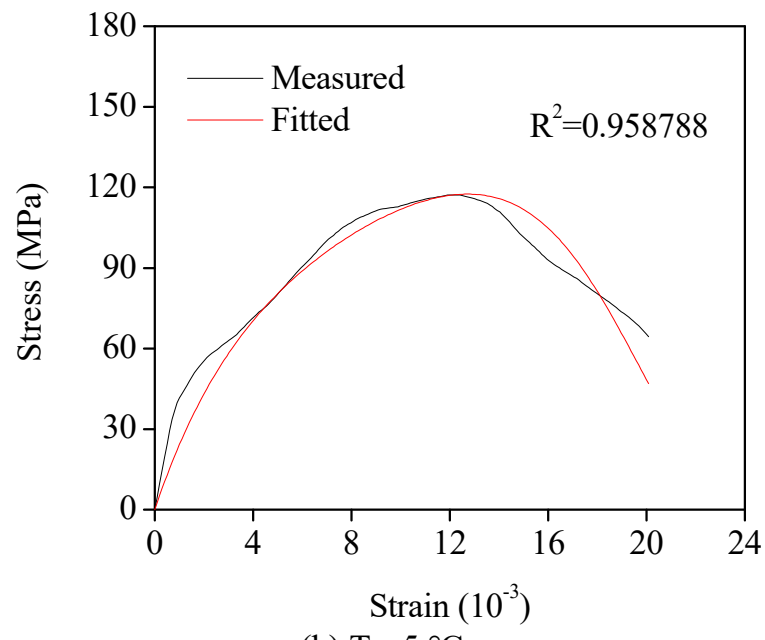

(b) $\mathrm{T}=-5^{\circ} \mathrm{C}$

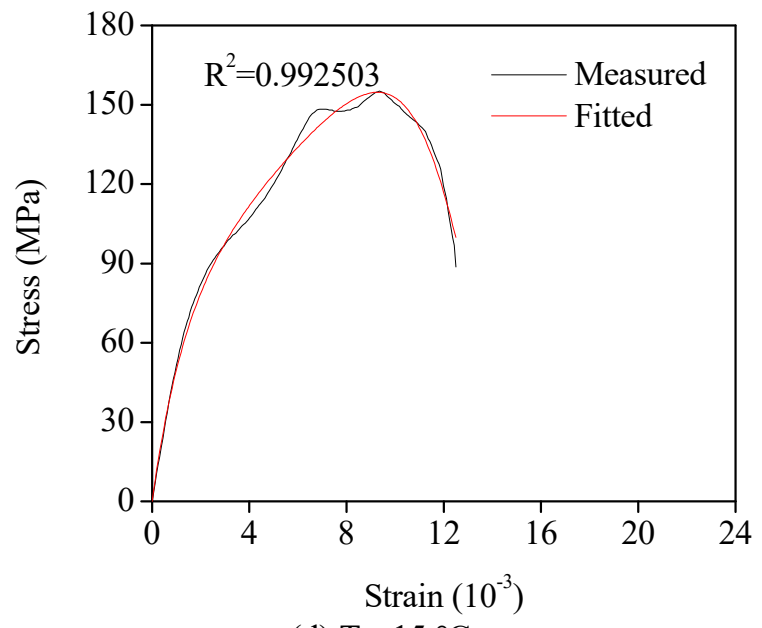

(d) $\mathrm{T}=-15^{\circ} \mathrm{C}$

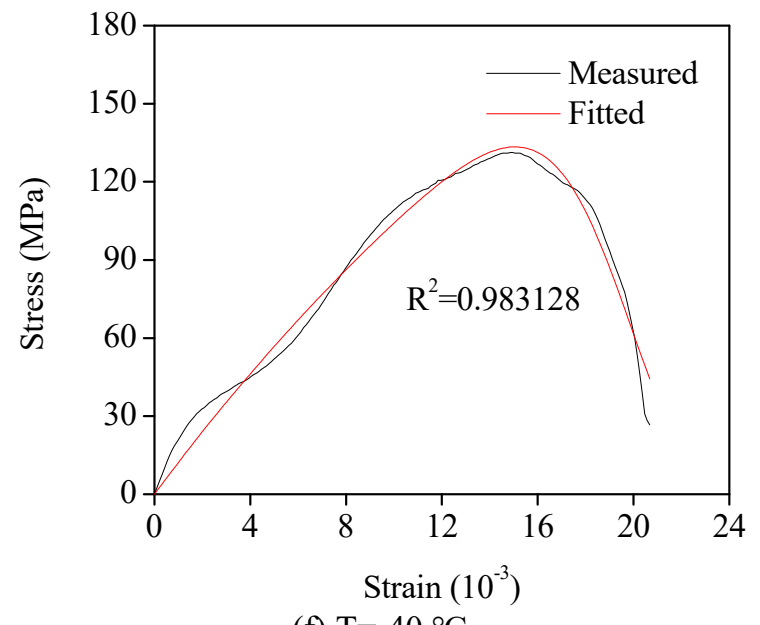

(f) $\mathrm{T}=-40^{\circ} \mathrm{C}$

Fig. 6 Comparison of stress-strain curves measured and fitted at strain rate $112 s^{-1}$ and different temperatures.

According to the definition of $D_{0}$ as 0 at $T=+25^{\circ} \mathrm{C}$, the damage of elastic modulus at different temperatures is shown in Table 4.

In order to study the law of the damage of elastic modulus changing with temperature, the trend of $D_{0}^{*}$ as a function of temperature is plotted and the functional relationship between $D_{0}^{*}$ and $T$ is fitted. Figure 7 shows the trend of $D_{0}^{*}$ as a function of temperature. The relationship between $D_{0}^{*}$ and $T$ is fitted by Eq. (27): 
Table 3 Fitting results of constitutive model parameters at strain rate $112 \mathrm{~s}^{-1}$ and different temperatures.

\begin{tabular}{ccrc}
\hline \multirow{2}{*}{$T /{ }^{\circ} \mathrm{C}$} & \multicolumn{3}{c}{ Model parameters } \\
\cline { 2 - 4 } & $D_{0}$ & \multicolumn{1}{c}{$\varphi / \mu s$} & $F_{0} / \mathrm{MPa}$ \\
\hline+25 & 0.515196 & 53.600074 & 211.413630 \\
-5 & 0.588516 & 29.738348 & 156.402454 \\
-10 & 0.255221 & 18.447047 & 205.251410 \\
-15 & 0.000000 & 12.073578 & 205.928989 \\
-20 & - & 3.547377 & 220.642228 \\
-40 & 0.665934 & & \\
\hline
\end{tabular}

$D_{0}^{*}=p_{1} \exp \left(-\frac{T^{*}}{p_{3}}\right)+p_{2} \exp \left(-\frac{\left(T^{*}-p_{4}\right)^{2}}{p_{5}}\right)$

Where, $T^{*}$ is $(T+273.15) / 273.15$; the value of $p_{1}$ is $21478304.466873 ; \quad p_{2}$ is $-2.596390 ; \quad p_{3}$ is $0.049206 ; p_{4}$ is 0.921654 and $p_{5}$ i $8.182596 \times 10^{-4}$.

Figure 8 shows the trend of $F_{0}$ as a function of temperature. The relationship between $F_{0}$ and $T$ is fitted by Eq. (28):

$$
F_{0}=q_{1} \exp \left(-\frac{T^{*}}{q_{3}}\right)+q_{2} \exp \left(-\frac{\left(T^{*}-q_{4}\right)^{2}}{q_{5}}\right)
$$

Where, $T^{*}$ is $(T+273.15) / 273.15$; the value of $q_{1}$ is $3.346282 ; q_{2}$ is $114.392752 ; q_{3}$ is -0.262670 ; $q_{4}$ is 0.897870 and $q_{5}$ is $6.325380 \times 10^{-3}$.

Figure 9 shows the trend of $F_{0}$ as a function of temperature. The relationship between $F_{0}$ and $T$ is fitted by Eq. (29):

$$
\varphi=r_{1} \exp \left(-\frac{T^{*}}{r_{3}}\right)+r_{2} \exp \left(-\frac{\left(T^{*}-r_{4}\right)^{2}}{r_{5}}\right)
$$

Where, $T^{*}$ is $(T+273.15) / 273.15$; the value of $r_{1}$ is $2.926468 \times 10^{-3} ; \quad r_{2}$ is $262.392028 ; r_{3}$ is $-0.110960 ; r_{4}$ is 0.861728 and $r_{5}$ is $2.488716 \times 10^{-4}$.

The freezing of water in pores is different compared with large volume water (Liu et al., 2014): the smaller the pore size, the lower the freezing point of water in the pores is. Liu et al. (2016) carried out CT scanning experiments on frozen rocks under different temperature gradients and quantitatively analyzed the variation of ice content with temperature. The results show that when the temperature was higher than $-2{ }^{\circ} \mathrm{C}$, there are only two-phase medium containing water and rock matrix in the rock. The rock only contains two-phase medium of ice and rock matrix below $-20{ }^{\circ} \mathrm{C}$. A three-phase medium containing water, ice and rock matrix is present in the frozen rock at other temperatures.

It can be seen from Figure 7 and Figure 8 that the damage increases slightly (i.e., the elastic modulus decreases) when the temperature drops from normal to $-2{ }^{\circ} \mathrm{C} . F_{0}$ reflecting the rock material strength level decreases. In the range of $\left(-2{ }^{\circ} \mathrm{C},-20^{\circ} \mathrm{C}\right)$, the damage decreases (i.e., the elastic modulus increases), and $F_{0}$ reflecting the rock material strength level increases. In the range of $\left(-20{ }^{\circ} \mathrm{C},-38{ }^{\circ} \mathrm{C}\right)$, the damage increases (i.e., the elastic mode decreases), and $F_{0}$ reflecting the rock material strength level decreases. As the temperature continues to decrease from $-38{ }^{\circ} \mathrm{C}$, the damage increases (i.e., the elastic modulus decreases), and $F_{0}$ reflecting the rock material strength level decreases. With the decrease of temperature, the damage shows "N" shape.

The reason for the above phenomenon is shown as follows: When the temperature drops from normal to $-2{ }^{\circ} \mathrm{C}$, the rock matrix shrinks the tensile stress appears on the microfracture surface, and the microcracks expand, which eventually leads to the decrease of macroscopic stiffness and strength of rock specimen. In the range of $\left(-2{ }^{\circ} \mathrm{C},-20^{\circ} \mathrm{C}\right)$, with the decrease of temperature, the water condenses into ice. The shrinkage of rock matrix and water-ice phase transition result in the increase of tensile stress on the microfracture surface and the decrease of rock stiffness and strength are intensified. However, the ice makes the microfracture surface bond; the bond effect of ice is greater than the sum of the frost expansion effect of ice and the shrinkage of rock matrix. It leads to an increase in the macroscopic stiffness and strength of the rock. In the range of $\left(-20^{\circ} \mathrm{C},-38^{\circ} \mathrm{C}\right)$, the rock matrix and ice shrink at the same time, because the shrinkage coefficient of ice is greater than the rock matrix ice and rock separation, the adhesion of ice on the micro-fracture surface decreases with the decrease of temperature until 0 . The different rates of ice and rock shrinkage lead to a decrease in the macroscopic stiffness and strength of the rock. In the lower temperature range, the matrix shrinks and the macro stiffness and strength of rock further decrease. For intact rock with no or only a few micro-cracks, the above rule is not satisfied, which also indicates that micro-cracks of specimens are relatively developed (Yang, 2016).

Table 4 Damage of elastic modulus at different temperatures is defined based on $D_{0}^{*}=0$ at $T=+25^{\circ} \mathrm{C}$.

\begin{tabular}{ccccccc}
\hline$T /{ }^{\circ} \mathrm{C}$ & +25 & -5 & -10 & -15 & -20 & -40 \\
\hline$D_{0}^{*}$ & 0.000000 & 0.151236 & -0.536250 & -1.06269 & -2.436300 & 0.614013 \\
\hline
\end{tabular}




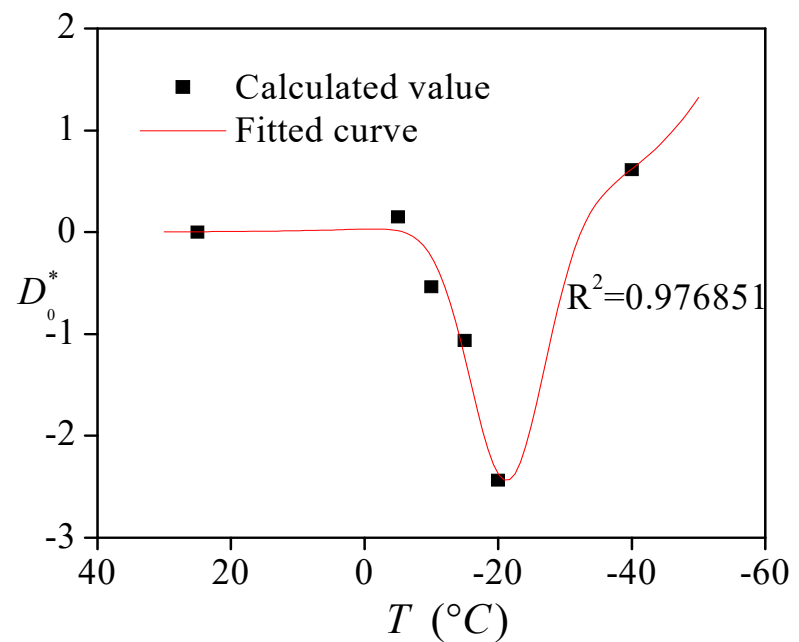

Fig. 7 Damage variation of low-temperature with temperature.

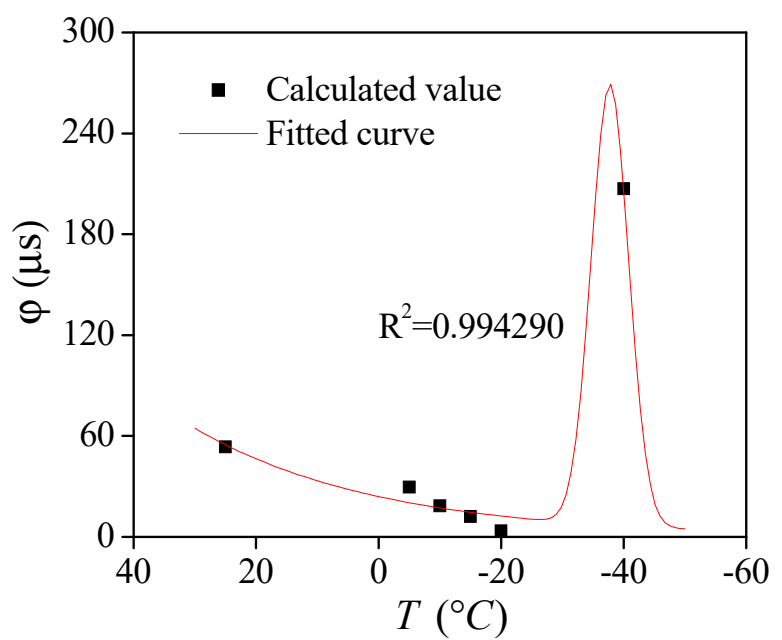

Fig. 9 Variation of $\varphi$ with temperature

6. VALIDATION OF THE CONSTITUTIVE MODEL WITH THE DAMAGE EFFECT OF LOW-TEMPERATURE

\subsection{VERIFICATION OF LOW-TEMPERATURE DAMAGE CONSTITUTIVE MODEL BY PARAMETER ANALYSIS}

The static elastic modulus of water-saturated marble at $T=+25^{\circ} \mathrm{C}$ is $4.800567 \mathrm{GPa}$ in this work. The value of $E_{0}$ measured by (Yang, 2016) is 3.67 GPa.

Because the test of elastic modulus is based on the method (Inada et al., 1984), the measured value of $E_{0}$ is definitely smaller than the actual value. Therefore, the static elastic modulus value of watersaturated marble obtained in this paper is acceptable and reasonable.

The peak stress of the water-saturated marble obtained through the test at strain rate $112 \mathrm{~s}^{-1}$ and different temperatures is shown in Table 5. The trend curves of $1-D_{0}^{*}, F_{0}$ and peak point stresses are

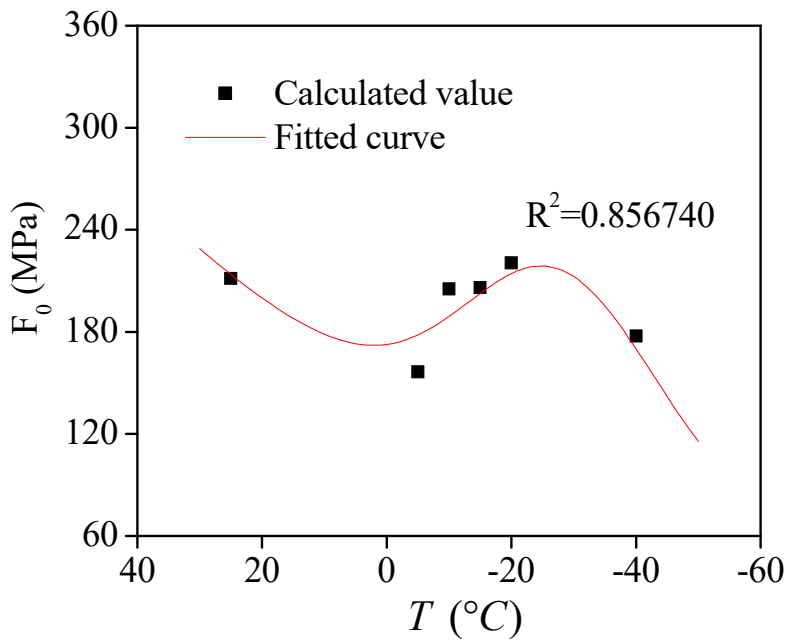

Fig. 8 Variation of $F_{0}$ with temperature

plotted according to Tables 3, 4 and 5. As a function of temperature, they are shown in Figure 10. $F_{0}$ is the reflection of strength level of the rock material, and the peak point stress is the stress intensity of the rock material. Thus $F_{0}$ and $\sigma_{\text {peak }}$ should have the same variation tendency. The content shown in Figure 10 just reflects this law. The variation of $1-D_{0}^{*}$ with temperature reflects the law of rock elastic modulus changing with temperature. The damage of elastic modulus can lead to the decrease of the rock material strength. Therefore, $1-D_{0}^{*}, F_{0}$ and $\sigma_{\text {peak }}$ should have the same change trend. The content shown in Figure 10 just reflects this rule.

\subsection{PREDICTION AND VERIFICATION OF CONSTITUTIVE MODEL OF LOW- TEMPERATURE DAMAGE}

By substituting Eq. (26) into the Eq. (18), the statistical damage constitutive model of the watersaturated rock under the coupling of temperature and the impact load can be further obtained:

$\sigma=\left(1-D_{0}^{*}\right) \exp \left(-\left(\frac{\left(1-D_{0}^{*}\right) E_{s} \varepsilon}{F_{0}}\right)^{m}\right) E_{s} \varepsilon$

Where, $E_{s}$ is $E_{0}^{*}+E_{1}^{*} \dot{\varepsilon} \varphi / \varepsilon(1-\exp (-\varepsilon / \dot{\varepsilon} \varphi)) ; \quad E_{0}^{*}$ and $E_{1}^{*}$ are the values of $E_{0}$ and $E_{1}$ at $T=+25^{\circ} \mathrm{C}$ respectively.

The stress-strain curves measured at $T=-30{ }^{\circ} \mathrm{C}$ and $\dot{\varepsilon}=112 \mathrm{~s}^{-1}$ are utilized to validate the proposed constitutive model considering the damage effect of low-temperature. By substituting $T=-30^{\circ} \mathrm{C}$ into Eq. (27), (28) and (29), and $E_{0}=9.90208 \mathrm{GPa}$ and $E_{1}=56.412452 \mathrm{GPa}$ into Eq. (30), the model parameters of water-saturated marble under the 
Table 5 Peak stress at strain rate $112 s^{-1}$ and different temperatures.

\begin{tabular}{ccccccc}
\hline$T /{ }^{\circ} \mathrm{C}$ & +25 & -5 & -10 & -15 & -20 & -40 \\
\hline$\sigma_{\text {peak }}$ & 158.30075 & 117.15932 & 144.75277 & 154.59535 & 161.88140 & 131.29537 \\
\hline
\end{tabular}

Table 6 Calculation results of constitutive model parameters at strain rate $112 \mathrm{~s}^{-1}$ and $-30{ }^{\circ} \mathrm{C}$.

\begin{tabular}{lccccccc}
\hline Symbol/ Unit & $T /{ }^{\circ} \mathrm{C}$ & $D_{0}^{*}$ & $E_{0}^{*}$ & $E_{1}^{*}$ & $\varphi / G P a$ & $F_{0} / M P a$ & $m$ \\
\hline Value & -20 & -0.440500 & 4.800567 & 27.34898 & 19.089599 & 198.751381 & 12.258390 \\
\hline
\end{tabular}

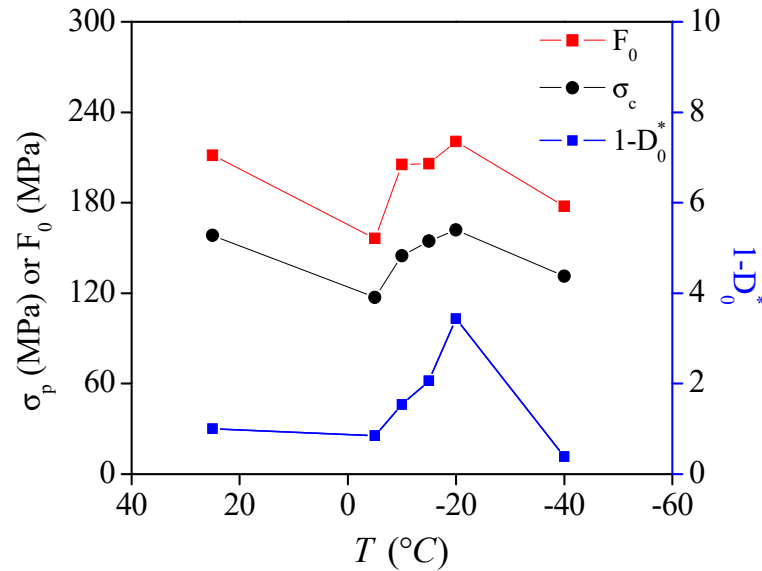

Fig. 10 Comparison of $1-D_{0}^{*}, F_{0}$ and $\sigma_{\text {peak }}$ with temperature.

condition of strain rate $112 \mathrm{~s}^{-1}$ and $-30{ }^{\circ} \mathrm{C}$ can be calculated shown in Table 6.

Table 6 is used to plot the stress-strain curves of water-saturated marble at strain rate $112 \mathrm{~s}^{-1}$ and $-30{ }^{\circ} \mathrm{C}$. As shown in Figure 11, the calculated curve and the experimental curve coincide well. The correlation coefficient reaches 0.984092 , which also indicates that the constitutive model of Eq. (25) is reasonable and effective.

\section{CONCLUSIONS}

In this paper, the statistical damage constitutive model of water-saturated marble under coupling effects of low-temperature and strain rate is established, and the model parameters are identified. Then the model is used to predict the dynamic stressstrain curve of water-saturated marble at $-30{ }^{\circ} \mathrm{C}$, and it is in good agreement with the test results. Through the research in this paper, the following main conclusions are drawn:

1. A parallel body composed of Hook spring and Maxwell body is adopted to simulate the viscoelasticity of rock materials in this paper. The elastic modulus of the parallel body is not the limit value (zero and positive infinity) under the limit loading conditions (strain rate is 0 and positive infinity). Therefore, the viscoelastic model is suitable for describing the deformation

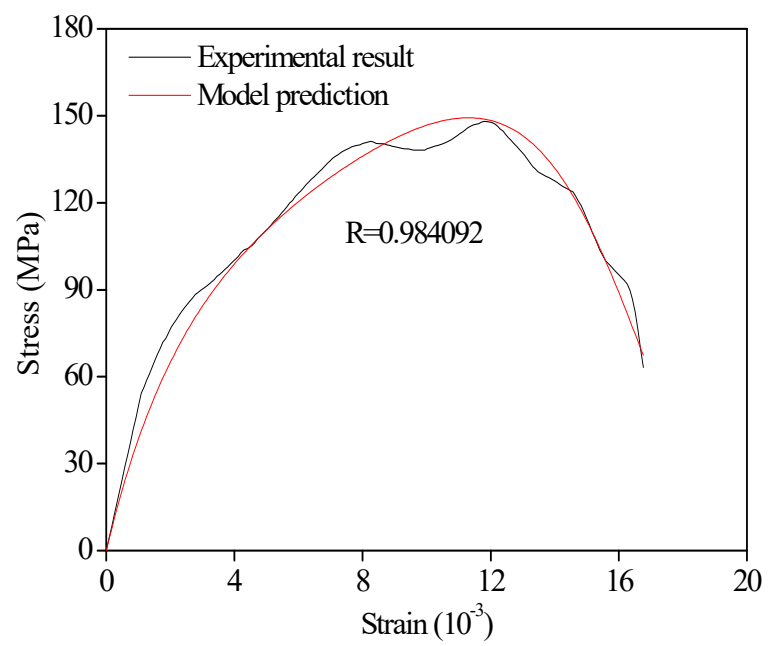

Fig. 11 Present model prediction (red line) for watersaturated marble at strain rate $112 \mathrm{~s}^{-1}$ and $-30{ }^{\circ} \mathrm{C}$ compared with the experimental results (black line).

of rocklike materials in the initial loading stage (undamaged stage).

2. The measured variable $F$ determined by the strength criterion of Drucker-Prager can be used for conditions of one-dimensional to threedimensional loading, which has been widely applied. In the Weibull distribution function describing the damage evolution law during loading, the parameter $F_{0}$ reflecting the average strength level of mesoscopic elements is related to the macro strength of rock materials. The parameter $m$ reflecting the difference in strength of mesoscopic elements is related to the brittleness of rock materials.

3. The damage law of water-saturated marble with temperature is not linear. With the decrease of temperature, the damage in "N" shape.

4. Through the theoretical analysis and experimental verification, the constitutive model of watersaturated marble under the coupling effects of uniaxial impact compression load and lowtemperature proposed in this paper is reasonable and effective. The relevant results can provide a theoretical reference for the excavation and impact protection of low-temperature rock engineering. 


\section{DATA AVAILABILITY}

The data used to support the findings of this study are available from the corresponding author upon request.

\section{ACKNOWLEDGEMENTS}

This research is supported by the National Natural Science Foundation for Young Scientists of China under Grant No. 51609184, the National Key Research and Development Program of China under Grant No. 2017YFC0804600, and China Postdoctoral Science Foundation under Grant No. 2016M602381.

\section{REFERENCES}

Cao, W.G., Zhao, H., Li, X. and Zhang, Y.J.: 2010, Statistical damage model with strain softening and hardening for rocks under the influence of voids and volume changes. Can. Geotech. J., 47, 8, 857-871. DOI: $10.1139 /$ T09-148

Deng, G. and Wang, G..: 2004, Analysis of characteristics of thermo-viscoelasto rheology of Beishan granite. Chin. J. Rock Mech. Eng., 23, Supp. 1, 4368-4372.

Hamdi, E., Romdhane, N.B. and Le Cléac'h, J.M.: 2011, A tensile damage model for rocks: Application to blast induced damage assessment. Comput. Geotech., 38, 2, 133-141. DOI: 10.1016/j.compgeo.2010.10.009

Inada, Y.K. and Yokota, K.: 1984, Some studies of lowtemperature of rock strength. Int. J. Rock Mech. Min., 21, 3, 145-153. DOI: 10.1016/0148-9062(84)91532-8

Lan, S., Lee, H.J., Lee S.H., Ni, J., Lai, X., Lee, H.W., Song, J.H. and Lee, M.G.: 2009, Experimental and numerical study on the viscoelastic property of polycarbonate near glass transition temperature for micro thermal imprint process. Mater. Design, 30, 9, 3879-3884. DOI: $10.1016 /$ j.matdes.2009.03.045

Lemaitre, J.: 1985, A continuous damage mechanics model for ductile fracture. J. Eng. Mater. Technol. (Trans. ASME), 107, 107, 83-89. DOI: 10.1115/1.3225775

Li, X., Zuo, Y., Wang, W., Ma, C. and Zhou, Z.: 2006, Constitutive model of rock under static-dynamic coupling loading and experimental investigation. $\mathrm{T}$. Nonferr. Metal. Soc., 16, 3, 714-722. DOI: 10.1016/S1003-6326(06)60127-1

Liu, H., Yang, G., Ye, W., Shen, Y. and Tang, L.: 2016, Analysis of ice content and damage characteristics of frozen rock based on pseudo-color enhanced CT image. Chin. J. Undergr. Sp. Eng., 12, 4, 912-919.

Liu, J., Xie, H., Hou, Z., Yang, C. and Chen, L.: 2014, Damage evolution of rock salt under cyclic loading in unixial tests. Acta Geotech., 9, 1, 153-160. DOI: $10.1007 / \mathrm{s} 11440-013-0236-5$

Liu, L., Wu, S., Chen, H. and Zhao, H.: 2014, Numerical investigation of the effects of freezing on microinternal damage and macro-mechanical properties of cement pastes. Cold Reg. Sci. Technol., 106-107, 141152. DOI: $10.1016 /$ j.coldregions.2014.07.003

Liu, Q.S., Xu, G.M. and Hu, Y.H.: 2006, Study on basic mechanical behaviors of rocks at low-temperature. Key Eng. Mater., 306-308, 1479-1484. DOI: 10.4028/www.scientific.net/KEM.306-308.1479

Liu, Y. and Dai, F.: 2018, A damage constitutive model for intermittent jointed rocks under cyclic uniaxial compression. Int. J. Rock Mech. Min., 103, 289-301. DOI: 10.1016/j.ijrmms.2018.01.046
Shan, R., Song, Y., Song, L., Huang, P., Dai, X. and Zhou, T.: 2018, Time dependent damage model of northwest artificial frozen red sandstone under dynamic loading. J. Chin. Coal Soc., 43, 1, 118-123. DOI: $10.13225 /$ j.cnki.jccs. 2017.0800

Wang, Z., Li, Y. and Wang, J.G.: 2007, A damage-softening statistical constitutive model considering rock residual strength. Comput. Geosci., 33, 1, 1-9. DOI: 10.1016/j.cageo.2006.02.011

Wang, Z.L., Shi, H. and Wang, J.G.: 2018, Mechanical behavior and damage constitutive model of granite under coupling of temperature and dynamic loading. Rock Mech. Rock Eng. 51, 10, 3045-3059. DOI: $10.1007 / \mathrm{s} 00603-018-1523-0$

Wen, M., Xu. J., Wang, H., Fang, X. and Zheng. G.: 2017, Fractography analysis of sandstone failure under lowtemperature-dynamic loading coupling effects. Chin. J. Rock Mech. Eng., 36, Supp. 3, 3822-3830. DOI: $10.13722 /$ j.cnki.jrme.2017.0514

Xiao, S. and Zhang, J.: 2010, Compressive damage experiment of concrete at different strain rates. Chin. Civil Eng. J., 43, 3, 40-45. DOI: $10.15951 /$ j.tmgcxb.2010.03.008

$\mathrm{Xu}$, G., Liu, Q., Peng. W. and Chang, X.: 2006, Experimental study on basic mechanical behaviors of rocks under low-temperatures. Chin. J. Rock Mech. Eng., 25, 12, 2502-2508. DOI: $10.1016 / \mathrm{S} 1872-1508(06) 60035-1$

Yamabe T. and Neaupane, K.M.: 2001, Determination of some thermo-mechanical properties of Sirahama sandstone under subzero condition. Int. J. Rock Mech. Min., 38, 7, 1029-1034. DOI: 10.1016/S1365-1609(01)00067-3

Yang, G., Xi, J., Li, H. and Cheng, L.: 2010, Experimental study of rock mechanical properties under triaxial compressive and frozen conditions. Chin. J. Rock Mech. Eng., 29, 3, 459-464.

Yang, Y.: 2016, Experimental study on dynamic mechanical properties of rock under low-temperature. (Doctoral dissertation, China University of Mining and Technology (Beijing)).

Zhai, Y., Zhao, J., Li, X. and Ren, J.: 2011, Study of damage viscoelasto-plastic dynamic constitutive model of rock material. Chin. J. Rock Mech. Eng., 30, Supp. 2, 38203824.

Zheng, Y., Xia, S. and Zhou, C.: 1997, Mechanism of dynamic elastic modulus of geotechnical materials. J. Vib. Shock, 16, 2, 56-61. DOI: 10.13465/j.cnki.jvs.1997.02.017

Zhou, S., Xia, C., Zhao, H., Mei, S. and Zhou, Y.: 2017, Statistical damage constitutive model for rocks subjected to cyclic stress and cyclic temperature. Acta Geophys., 65, 5, 893-906. DOI: $10.1007 / \mathrm{s} 11600-017-0073-2$

Zhou, Z., Li, X., Zou, Y., Jiang, Y. and Li, J.: 2014, Dynamic brazilian tests of granite under coupled static and dynamic loads. Rock Mech. Rock Eng., 47, 2, 495505. DOI: 10.1007/s00603-013-0441-4

Zhu, Z., Chen, S., Ling, X., Wang, L. and Li, Q.: 2013, Experiment study on dynamic parameters of artificial polycrystalline ice. Chin. J. Geotech. Eng., 35, 4, 762766.

Zuo, Q.H., Disilvestro, D. and Richter, J.D.: 2010, A crackmechanics based model for damage and plasticity of brittle materials under dynamic loading. Int. J. Solids Struct., 47, 20, 2790-2798. DOI: $10.1016 /$ j.ijsolstr.2010.06.009 